\title{
Local Economic Inequality and the Primary Care Physician Workforce in North Carolina
}

\author{
Joseph Nenow, MD, Andrew Nenow, Allison Priest, Kendall M. Campbell, MD, and \\ Dmitry Tumin, PhD
}

Background: Income inequality has been associated with multiple adverse health outcomes including diabetes and obesity, with this relationship potentially mediated by limited access to primary care. We explore the association between county-level economic inequality and the primary care physician (PCP) workforce in North Carolina.

Methods: County-level economic and demographic data were obtained for 2013 to 2018 . Economic inequality was quantified using the Gini coefficient of household income. PCP workforce data were obtained from a statewide database and correlated with county characteristics using fixed-effects linear regression.

Results: The analysis included 600 county-years. An increase of 0.1 in the Gini coefficient was correlated with a decrease in PCP workforce by 0.58 physicians $/ 1000$ residents in a given county. Within family medicine, a 0.1 increase in the Gini coefficient was associated with a decrease of 0.53 family medicine physicians per 1000 residents.

Conclusions: Local increases in economic inequality are associated with local decreases in PCP workforce (per capita), particularly in family medicine. Although further research is needed to identify specific reasons for the decrease, medical schools in areas with high economic inequality should consider prioritizing training of physicians in family medicine and other primary care specialties to better serve community health care needs. (J Am Board Fam Med 2022;35:35-43.)

Keywords: Access to Health Care, Family Medicine, Gini Coefficient, Health Care Outcome Assessment, Income, North Carolina, Population Health, Primary Care Physicians, Primary Health Care, Surveys and Questionnaires, Workforce

\section{Introduction}

Income inequality in the United States has increased since the 1980s, reinvigorating the debate over how material inequality affects population health and well-being. ${ }^{1}$ Poverty is a known contributor to poor health outcomes, with documented associations to prevalence of lifestyle-related

This article was externally peer reviewed.

Submitted 21 March 2021; revised 21 July 2021 and 16 August 2021; accepted 18 August 2021.

From Brody School of Medicine, East Carolina University, Greenville NC (JN); University of North Carolina-Chapel Hill, Chapel Hill NC (AN); Department of Pediatrics, Brody School of Medicine, East Carolina University, Greenville NC (AP, DT); Research Group for Underrepresented Minorities in Academic Medicine, Division of Academic Affairs, Brody School of Medicine, East Carolina University (KMC).

Funding: none.

Conflict of interest: No authors have any reported conflicts of interest, financial or otherwise.

Corresponding author: Joseph Nenow, MD, Brody School of Medicine at East Carolina University, 600 Moye Blvd, Greenville, NC 27834 (E-mail: josephnenow@gmail.com). chronic diseases including diabetes, cardiovascular disease, and obesity. ${ }^{2,3}$ Societal or community income inequality — not only individual poverty-is also adversely associated with health status. ${ }^{4-7}$ Observational studies have linked population inequality with adverse effects on longevity, functional status, and quality of life. ${ }^{8,9}$ Such studies have often focused on the Gini coefficient of inequality, which measures the concentration of wealth or income in a given population, and its association with health outcomes.

Explanations for the health impact of population income inequality have drawn on various sociological and economic theories. The most recent investigations highlight potential relationships with stress, structural racism, and community underinvestment in public health. ${ }^{10-12}$ Geographic areas with high inequality had higher rates of preventable hospital admissions and were more likely to report unmet health care needs. ${ }^{13-15}$ In turn, reduced access to primary and preventive care has been suggested as a 
mechanism by which economic inequality leads to poor health outcomes. ${ }^{16}$ Primary care access has been proposed as a potential target for intervention to improve population health in economically unequal communities and societies. While access to primary care is multifactorial, a key determinant is the available workforce of primary care physicians (PCPs), which is likely to be sensitive to community differences in investment in primary care.,

Current research on the connection between the primary care workforce and income inequality has yielded mixed results. While a correlation exists between higher income inequality and worse health outcomes in the United States, this relationship is not seen in other countries, such as Canada, perhaps due to the existence of a universal health care system. $^{7}$ Evidence on the correlation between access to care and income inequality also varies by the geographic scale of each study. One US study has discovered correlation between higher statelevel inequality and lower PCP supply. ${ }^{15}$ In contrast, 2 neighborhood-level analyses found that income inequality was not associated with access to care. ${ }^{17,18}$ Recent evidence has linked county-level economic inequality with health outcomes through the closely related metric of primary care access. ${ }^{14,19}$ County governments have an active role in allocating resources to health care services (in contrast to smaller geographic units such as neighborhoods, which lack administrative authority to shape health care delivery). Because of this, counties were chosen as the most appropriate geographic unit of analysis for this study.

Considering these conflicting results, we aimed to analyze the association between county-level income inequality and the PCP workforce in North Carolina. Historic racism in North Carolina should be considered a notable factor for the racial disparity in economic status, where Black households and household of color are almost twice as likely to have a net worth below zero dollars. ${ }^{20,21}$ Whereas recent research has found the Affordable Care Act to have reduced income inequality in states that have expanded Medicaid access, ${ }^{21}$ North Carolina is one of a minority of states that have chosen not to expand Medicaid, and one of a few states in the United States where income inequality increased since the 2009 recession. As such, this state presents an important case study for considering the relationships between government underinvestment in health care, growth in inequality, and decline in the per-capita primary care workforce. ${ }^{16,22}$ Our main hypothesis was that as economic inequality in each North Carolina county increased, the number of PCPs per capita would decrease. Our secondary aim was to compare this association by specialty (particularly, family medicine and pediatrics).

\section{Methods}

The study was reviewed by the institutional review board (IRB) at East Carolina University, which determined that our study did not meet the definition of human subjects research and did not require IRB review. County-level economic inequality data were obtained from the 5-year American Community Survey (ACS) estimates for the years 2013 to 2018 (where 2013 refers to the 2009 to 2013 pooled data, 2014 refers to the 2010 to 2014 pooled data, and likewise for most recent years). ${ }^{23}$ Economic inequality was quantified using the Gini coefficient of household income, defined as the statistical dispersion of income in a given population with a range between 0 to 1 , with 0 describing perfect equality and 1 describing perfect inequality. ${ }^{24}$ In 2017, the Gini coefficient for the United States as a whole was $0.434 .^{25}$ County-level health care workforce data were originally collected by the NC state medical board and subsequently obtained from NC Health Workforce, which collects data on health care providers from profession-specific licensing boards and reports workforce data on a per-capita basis. ${ }^{26}$ Data on PCPs were available annually from 2013 to 2018, and PCP workforce data from each year were matched to data on income inequality from the ACS. Data on nonphysician providers were excluded from analysis as nonphysician workforce data were not subdivided by specialty during the study period. With North Carolina subdivided into 100 counties, the analysis included a sample of 600 observations (1 for each county and year).

In the NC Health Workforce database, PCPs were a predefined group consisting of physicians whose primary area of practice was adolescent medicine, family medicine, general practice, internal medicine, internal medicine-pediatrics, obstetrics/ gynecology, or pediatrics. More granular data on subspecialties within pediatrics or internal medicine were not available in the public-use files. For our 
primary analysis, we correlated the per-capita PCP workforce in each county with the contemporaneous county-level measure of income inequality (Gini coefficient). In secondary analyses, we examined per-capita availability of family medicine physicians and pediatricians to determine if the workforce in different primary care specialties was differentially associated with income inequality.

Drawing on previous work, potential confounders were assessed at the county level using ACS data and included median age in the county, percent of adults with a college degree, median family income, gender composition, race/ethnicity composition, average family size, and percent males married above age $18 .^{18}$ Counties were classified as rural based on population density less than 96.5 persons/square kilometer. ${ }^{27}$ In the analysis of the pediatrician workforce, we also performed a sensitivity analysis using the percentage of county population $<18$ years old as the age measure.

Data were summarized using medians and interquartile ranges (IQRs). Bivariate analysis of inequality and per-capita primary care workforce was performed using Spearman correlation coefficients. To isolate the effect of changing income inequality on the primary care workforce in each county, we used fixed-effects linear regression models, where change in each county's workforce was estimated based on change in that county's income inequality over time. ${ }^{28}$ Models were adjusted for calendar year and all time-varying covariates. Data analysis was completed using Stata/S.E. 15.1 (StataCorp, LP,
College Station, TX) and RStudio (Rstudio, LLC, Boston, MA). $P<.05$ was considered statistically significant.

\section{Results}

Data for the $100 \mathrm{NC}$ counties were collected for 2013 to 2018, for a total of 600 county-years. County characteristics for the latest year are summarized in Table 1. The median Gini coefficient across counties was 0.46 (IQR $0.44,0.47$ ). Inequality was greater in urban areas than in rural areas (mean Gini coefficient of 0.46 in urban vs 0.45 in rural counties, as of 2018). The median number of physicians per thousand residents was $5.0(3.5,6.7)$ for all PCPs, 2.4 (IQR 1.6, 3.2) for family medicine physicians, and 0.9 (IQR 0.4, 1.3) for pediatricians. Over the study period, 72 counties experienced an increase in the Gini coefficient, with the largest increase occurring in Greene County (from 0.40 to 0.45). A greater proportion of urban counties than rural counties experienced an increase in inequality ( $86 \%$ of urban counties vs $67 \%$ of rural counties), but among rural counties experiencing rising economic inequality, the increase in inequality was larger than in urban counties (mean Gini increase of 0.02 in rural counties vs 0.01 in urban counties).

On bivariate analysis, higher Gini coefficients were positively associated with the number of primary care physicians, family medicine physicians, and pediatricians per 1000 residents $(r h o=0.34$,

Table 1. Characteristics of North Carolina Counties in 2018 ( $n=100$ Counties)

\begin{tabular}{lc}
\hline Variable & N (\%) or Median (IQR) \\
\hline Gini coefficient of income inequality & $0.46(0.44,0.47)$ \\
Physician workforce per 1000 residents & $5.0(3.5,6.7)$ \\
$\quad$ Primary care & $2.4(1.6,3.2)$ \\
$\quad$ Family medicine & $0.9(0.4,1.3)$ \\
$\quad$ Pediatrics & $80(80 \%)$ \\
Rural county & $19(15,25)$ \\
Percent of adults with college degree & $45(39,51)$ \\
Median family income (\$1000s) & $2.5(2.4,2.6)$ \\
Average family size & $52(48,56)$ \\
Percent of males who are married (18+) & $49(48,50)$ \\
Percent male & $19(6,34)$ \\
Percent Black or African American & $6(4,10)$ \\
Percent Hispanic or Latino & $43(40,46)$ \\
Median age (years) & $21(19,23)$ \\
\hline
\end{tabular}

Abbreviation: IQR, interquartile range. 
Table 2. Fixed-Effects Regression of County-Level Primary Care Physician Workforce per 1000 Residents, 20132018 ( $n=600$ County-Years)

\begin{tabular}{lccc}
\hline Variable & Coefficient & $95 \%$ CI & $P$ \\
\hline Gini coefficient $\times 10$ & -0.58 & $-1.12,-0.04$ & 0.036 \\
Year & 0.03 & $-0.04,0.11$ & 0.374 \\
Percent of adults with college degree & 0.08 & $0.02,0.14$ & 0.005 \\
Median family income (\$1000s) & -0.03 & $-0.06,0.01$ & 0.205 \\
Average family size & 0.12 & $-0.07,0.30$ & 0.223 \\
Percent of males who are married (18+) & -0.02 & $-0.05,-0.001$ & 0.045 \\
Percent male & -0.18 & $-0.30,-0.05$ & 0.006 \\
Percent Black or African American & 0.09 & $-0.01,0.19$ & 0.071 \\
Percent Hispanic or Latino & 0.04 & $-0.14,0.22$ & 0.644 \\
Median age (years) & -0.01 & $-0.13,0.12$ & 0.904 \\
\hline
\end{tabular}

Abbreviation: CI, Confidence interval.

0.19 , and 0.33 , respectively; all $P<.001$ ), although this correlation conflated differences across counties at the same time point and differences over time in the same county. On multivariable fixedeffects analysis (Table 2), we examined the withincounty association between Gini coefficient and PCP workforce, adjusting for other time-varying measures. In a given country, a 0.1 point increase in the Gini coefficient was correlated with a decrease in the PCP workforce by 0.58 physicians $/ 1000$ residents (95\% CI, $-1.12,-0.04 ; P=.036)$. Meanwhile, a $1 \%$ increase over time in the percent of adults with a college degree was associated with an increase in the PCP workforce by 0.08 physicians/ 1000 residents ( $95 \% \mathrm{CI}, 0.02,0.14 ; P=.005)$, and a $1 \%$ increase in the proportion of residents who are male was associated with a decrease in the PCP workforce by 0.18 physicians $/ 1000$ residents ( $95 \%$ CI, $-0.30,-0.05 ; P=.006)$.
Focusing on family medicine and pediatrics in particular (Tables 3 and 4, respectively), we found differences between these specialties in the estimated impact of increasing economic inequality. A 0.1 increase in the Gini coefficient was associated with a decrease of 0.53 family medicine physicians per 1000 residents (95\% CI, $-0.94,-0.12 ; P=.011)$ but no statistically significant change in the number of pediatricians per 1000 residents $(+0.20$; $95 \%$ CI, $-0.01,0.42$; $P=.064)$. In the analysis of the pediatrician workforce, older median age was associated with a greater number of pediatricians per capita $(+0.05 / 1000$ for each 1 year increase in median age; $95 \% \mathrm{CI},+0.003,+0.10$; $P=.037)$. When refitting this model using percent of the population $<18$ years old as the age measure, we confirmed no association between the Gini coefficient and the pediatrician per-capita workforce but found that increases in the proportion of the population age $<18$ years were associated with decreases in the

Table 3. Fixed-Effects Regression of County-Level Family Medicine Physician Workforce per 1000 Residents, 2013-2018 ( $n=600$ County-Years)

\begin{tabular}{lccr}
\hline Variable & Coefficient & $95 \%$ CI & $P$ \\
\hline Gini coefficient $\times 10$ & -0.53 & $-0.94,-0.12$ & 0.011 \\
Year & 0.05 & $0.00,0.11$ & 0.056 \\
Percent of adults with college degree & 0.05 & $0.004,0.09$ & 0.033 \\
Median family income (\$1000s) & -0.01 & $-0.04,0.02$ & 0.475 \\
Average family size & 0.14 & $0.001,0.283$ & 0.048 \\
Percent of males (18+) who are married & 0.00 & $-0.02,0.01$ & 0.712 \\
Percent male & -0.11 & $-0.21,-0.02$ & 0.018 \\
Percent Black or African American & 0.09 & $0.02,0.16$ & 0.018 \\
Percent Hispanic or Latino & 0.08 & $-0.06,0.21$ & 0.281 \\
Median age (years) & -0.03 & $-0.12,0.07$ & 0.588 \\
\hline
\end{tabular}

Abbreviation: CI, Confidence interval. 
Table 4. Fixed-Effects Regression of County-Level Pediatrician Workforce per 1000 Residents, 2013-2018 $(\mathrm{n}=$ 600 County-Years)

\begin{tabular}{|c|c|c|c|c|c|c|}
\hline \multirow[b]{2}{*}{ Variable } & \multicolumn{3}{|c|}{ Primary Analysis } & \multicolumn{3}{|c|}{ Sensitivity Analysis* } \\
\hline & Coefficient & $95 \% \mathrm{CI}$ & $P$ & Coefficient & $95 \% \mathrm{CI}$ & $P$ \\
\hline Gini coefficient $\times 10$ & 0.20 & $-0.01,0.42$ & 0.064 & 0.19 & $-0.02,0.40$ & 0.081 \\
\hline Year & -0.02 & $-0.05,0.01$ & 0.209 & -0.04 & $-0.07,-0.01$ & 0.008 \\
\hline Percent of adults with college degree & 0.02 & $0.00,0.04$ & 0.094 & 0.02 & $-0.003,0.04$ & 0.085 \\
\hline Median family income (\$1000s) & -0.01 & $-0.03,0.00$ & 0.064 & -0.01 & $-0.03,0.00$ & 0.108 \\
\hline Average family size & -0.09 & $-0.16,-0.01$ & 0.020 & -0.08 & $-0.15,-0.002$ & 0.045 \\
\hline Percent of males $(18+)$ who are married & -0.01 & $-0.02,-0.003$ & 0.020 & -0.01 & $-0.02,-0.001$ & 0.025 \\
\hline Percent male & 0.00 & $-0.05,0.05$ & 0.928 & -0.04 & $-0.9,0.02$ & 0.178 \\
\hline Percent Black or African American & -0.04 & $-0.08,-0.001$ & 0.046 & -0.06 & $-0.10,-0.02$ & 0.005 \\
\hline Percent Hispanic or Latino & -0.02 & $-0.10,0.05$ & 0.538 & 0.01 & $-0.06,0.09$ & 0.742 \\
\hline Median age (years) & 0.05 & $0.003,0.10$ & 0.037 & & & \\
\hline Percent population $<18$ years old & & & & -0.14 & $-0.21,-0.07$ & $<0.001$ \\
\hline
\end{tabular}

Abbreviation: CI, Confidence interval.

*The sensitivity analysis used percent population $<18$ years old as the age measure in each county and year, rather than median age, as an alternative strategy to account for the size of the pediatric population and associated demand for pediatricians.

pediatrician workforce size $(-0.14 / 1000$ for each $1 \%$ increase in the population proportion age $<18$ years; 95\% CI, $-0.21,-0.07 ; P<.001)$.

\section{Discussion}

Limited access to primary care is one of the mechanisms proposed to explain the association between economic inequality and poor population health. ${ }^{29}$ In this study, we used a within-county longitudinal design to demonstrate that as economic inequality increased, the number of PCPs per capita declined in a southeastern state in the United States. Within specialty-specific analysis, this pattern was observed for family medicine physicians and not for pediatricians. In addition, we observed a concerning trend wherein increasing pediatric populations within a county were accompanied by a decrease rather than increase in the per-capita pediatrician workforce. These 2 specialties (ie, pediatrics and family medicine) were chosen for further individual investigation due to their size, ease in identifying general practitioners, and importance in the context of the state refusal to expand Medicaid. Building on prior cross-sectional analyses of income inequality and population health, our study disentangles the longitudinal association between these factors from cross-sectional differences in the concentration of physicians between rural areas (which tend to have lower levels of inequality) and urban areas (where inequality tends to be higher). ${ }^{14}$ With the economic shock of the COVID19 pandemic exacerbating the pre-existing trend toward greater economic inequality, further work is needed to understand how the PCP workforce, especially the workforce of family medicine physicians, can be preserved and expanded to meet the health needs of disadvantaged communities. ${ }^{30}$

At the national level, the United States is expected to experience a shortage of 21,400-55,200 PCPs by 2033, with poverty and rurality influencing this shortage. ${ }^{31,32}$ The PCP shortage is also observed internationally. In many Organization for Economic Cooperation and Development countries, a component of this shortage can be attributed to a decline in interest of pursuing primary careers. ${ }^{33-35}$ Because it is challenging to quantify the rate at which practitioners of traditional primary care specialties continue to semispecialize, the extent of this shortage may be underestimated. ${ }^{36}$ Impoverished urban areas may be experiencing particularly rapid exacerbation of the PCP shortage, ${ }^{37}$ but the negative effects of PCP shortage may be especially felt in rural areas due to their historic experience of poor health outcomes and lack of access to medical care. Rural areas are consistently documented to have worse population health indicators as well as limited access to mental health services, decreased testing for chronic disease, and increased risk of lacking a usual source of health care. ${ }^{37}$

In North Carolina, our study shows that a higher proportion of urban counties experienced an increase in inequality. However, the magnitude of this increase was greater in the rural counties where 
inequality increased over the study period. Rural counties with growing inequality may be the most susceptible to large gaps between the demand for primary care and the supply of PCPs. In these counties, exacerbation of the PCP shortage means that already limited health resources would be stretched further, leading to increasing unmet needs for primary and preventive care. As North Carolina has chosen not to expand Medicaid, providers may be hesitant to practice in rural locations due to perceived poor compensation or limited potential to provide care to patients who lack insurance. ${ }^{38,39}$

Nonphysician health care providers (ie, physician assistants [PAs] and nurse practitioners [NPs]) have been proposed as a solution to limited access to care, and the supply of providers in these roles may be an important confounder of the relationship between inequality and access to physicians in primary care specialties. Our analysis did not examine PA and NP workforce trends for several reasons. NC Health Workforce, the source for health care workforce data in our study, contains physician workforce data stratified by medical specialty since 2013 but does not include stratification by practice area for PAs and NPs over this entire period. Workforce patterns also vary significantly between physicians and PAs or NPs. Despite enthusiasm for PA-mediated rural primary care, the overwhelming majority of PAs work in nonrural areas, and only a third practice primary care. ${ }^{40,41}$ In addition, due to the ease of switching between practice areas and the older age of rural PAs, the percent of PAs in primary care has historically declined at a rate of $0.3 \%$ per year. $^{40}$

The increase in income inequality may be considered a symptom of broader social, political, and economic trends with ties to institutional racism, financial deregulation, and the financialization of the economy. ${ }^{42-44}$ Historically, periods of low inequality were marked by a rising minimum wage, low levels of unemployment, caps on executive compensation, and widespread collective bargaining. ${ }^{22}$ In recent years, the share of wealth possessed by the bottom $90 \%$ of US households has decreased by approximately $10 \%$, while the wealthiest $1 \%$ of the population has increased their wealth by a similar margin. ${ }^{45}$ The COVID-19 pandemic has exacerbated these trends. Massive shifts in the distribution of labor and economic resources have disproportionately disadvantaged ethnic and racial minorities via higher unemployment and decreased access to care. ${ }^{46-48}$ As our findings suggest, this acute exacerbation of inequality can potentially have significant and long-lasting adverse consequences for primary care access across the United States.

Despite the timeliness of this analysis, our study is subject to limitations associated with available data and the analytic approach. Census data were obtained from ACS estimates, which are subject to measurement error. To minimize potential for error, we followed Census Bureau recommendations by using the combined 5-year ACS estimates for small geographies such as counties. Decreased access to physician care may also be associated with an increase in access to nonphysician health care provider care. However, in our analysis data on nonphysician primary care providers were not analyzed because these data were not disaggregated by practice type. Furthermore, groupings such as "Primary Care Physicians" were predetermined by NC Health Workforce, and choices for included specialties (eg, the inclusion of obstetrics and gynecology but exclusion of geriatrics) could not be altered. In addition, as with prior observational studies, we cannot identify a causal effect between economic inequality and the size of the PCP workforce. In particular, we were unable to analyze how changes in economic inequality influenced community action or political decisions related to investment in health care, which is the presumed mechanism by which increasing inequality might be associated with decreased PCP availability.

As a further limitation, our data were obtained from a state where some of the fastest growth in inequality has been seen following the Great Recession. As such, our results may not be generalizable to other states in the United States. Generalizability of results is also limited by the model of health care delivery in which general practitioners (GPs), family physicians, and PCPs are often used interchangeably. We did not consider other models of care used outside the United States that require referral from GPs or family physicians to access specialty care. We were also unable to account for reported trends of increasing specialization of family physicians who opt out of full-scope community practice. Our analysis focused on the number of physicians currently in the workforce but not the contribution of community-based medical schools, which are on the frontline of training additional 
PCPs to meet the health care needs of rural and underserved communities. ${ }^{49}$ Finally, demographic groups with lower average incomes-such as immigrants and workers without a college degree-were most likely to have experienced a loss in job or income due to the COVID-19 pandemic. ${ }^{50}$ As a result, the effects of changes in employment and migration on county-level access to care could not be considered.

The continued rise of economic inequality has been associated with worse health outcomes for people in the US and abroad. As one of a few states in the United States where inequality has continued to increase since the Great Recession, North Carolina's recent experience with rising inequality may foreshadow the impact of growing inequality in the wake of the COVID-19 pandemic. Our fixed-effects analysis specifically evaluated how within-county change in inequality was associated with the PCP workforce, and this association may follow a different pattern from cross-sectional associations comparing different counties, metropolitan areas, or regions. Between 2013 and 2018, our study found that as NC counties became more economically unequal, the per-capita supply of PCPs, and especially family medicine physicians, tended to decrease. Further studies should expand the scope of this analysis by considering the relationship between inequality and the supply of PA and NP primary care providers. While root causes of economic inequality are complex and require interventions at the national scale, these local consequences of economic inequality are a call to action for medical schools in economically unequal states and communities. As location of residency is associated with location of medical practice regardless of rural/urban setting, investment in local primary care physician training may be a method by which communities can support access to primary care that is resilient to trends in economic inequality. ${ }^{51,52}$

To see this article online, please go to: http://jabfm.org/content/ 35/1/35.full.

\section{References}

1. United States Census Bureau [Internet]. Gini index of money income and equivalence-adjusted income: 1967 to 2014; 2015 [cited 2020 Sept 12]. Available from: https://www.census.gov/library/visualizations/ 2015/demo/gini-index-of-money-income-andequivalence-adjusted-income-1967.html.

2. Rabi DM, Edwards AL, Southern DA, et al. Association of socio-economic status with diabetes prevalence and utilization of diabetes care services. BMC Health Serv Res 2006;6:124.

3. Lemstra $M$, Rogers $M$, Moraros J. Income and heart disease: neglected risk factor. Can Fam Physician 2015;61:698-704.

4. McLaughlin DK, Stokes CS. Income inequality and mortality in US counties: does minority racial concentration matter? Am J Public Health 2002;92:99104.

5. Yang $W, \mathrm{Li} H, F u X, L u J$, Xue Z, Wu C. Inequalities in cardiovascular health between local and migrant residents: a cross-sectional study of 6934 participants in Longhua District, Shenzhen. Med (United States) 2015;94.

6. Lim D, Bahk J, Ock M, et al. Income-related inequality in quality-adjusted life expectancy in Korea at the national and district levels. Health Qual Life Outcomes 2020;18:45.

7. Lynch J, Smith GD, Harper S, et al. Is income inequality a determinant of population health? Part 1. A systematic review. Milbank Q 2004;82:5-99.

8. Chetty R, Stepner M, Abraham S, et al. The association between income and life expectancy in the United States, 2001-2014. JAMA 2016;315:1750-66.

9. Vega WA, Sribney WM. Growing economic inequality sustains health disparities. Am J Public Health 2017;107:1606-7.

10. Bell CN, Owens-Young JL. Self-rated health and structural racism indicated by county-level racial inequalities in socioeconomic status: the role of urban-rural classification. J Urban Health 2020;97: 52-61.

11. Yearby R. Racial disparities in health status and access to healthcare: the continuation of inequality in the United States due to structural racism. Am J Econ Sociol 2018;77:1113-52.

12. Bailey ZD, Krieger N, Agénor M, Graves J, Linos $\mathrm{N}$, Bassett MT. Structural racism and health inequities in the USA: evidence and interventions. Lancet 2017;389:1453-63.

13. Bettenhausen JL, Colvin JD, Berry JG, et al. Association of income inequality with pediatric hospitalizations for ambulatory care-sensitive conditions. JAMA Pediatr 2017;171:e170322.

14. Tumin D, Menegay M, Shrider EA, Nau M, Tumin R. Local income inequality, individual socioeconomic status, and unmet healthcare needs in Ohio, USA. Health Equity 2018;2:37-44.

15. Shi L, Starfield B. The effect of primary care physician supply and income inequality on mortality among Blacks and Whites in US metropolitan areas. Am J Public Health 2001;91:1246-50.

16. Shi L, Macinko J, Starfield B, Wulu J, Regan J, Politzer R. The relationship between primary care, income inequality, and mortality in US states, 1980-1995. J Am Board Fam Pract 2003;16:412-22. 
17. Mudd AE, Michael YL, Melly S, Moore K, DiezRoux A, Forrest CB. Spatial accessibility to pediatric primary care in Philadelphia: an area-level cross sectional analysis. Int $\mathrm{J}$ Equity Health 2019;18:1-7.

18. Hussein M, Diez Roux AV, Field RI. Neighborhood socioeconomic status and primary health care: usual points of access and temporal trends in a major US urban area. J Urban Health 2016; 93:1027-45.

19. López DB, Loehrer AP, Chang DC. Impact of income inequality on the nation's health. J Am Coll Surg 2016;223:587-94.

20. Aurelien M [Internet]. Without adequate policy changes, the racial wealth gap may never allow for prosperity for all. North Carolina Justice Center; 1995 [cited 2020 Sept 13]. Available from: https:// www.ncjustice.org/publications/without-adequatepolicy-changes-the-racial-wealth-gap-may-never-allowfor-prosperity-for-all/\#_ftn2.

21. Buettgens M, Blavin F, Pan C. The Affordable Care Act reduced income inequality in the US. Health Aff (Millwood) 2021;40:121-9, https://doi. org/101377/hlthaff201900931.

22. Sommeiller E, Price M [Internet]. The new gilded age: income inequality in the U.S. by state, metropolitan area, and county; 2018 [cited 2020 Sept 12]. Available from: https://www.epi.org/publication/ the-new-gilded-age-income-inequality-in-the-u-sby-state-metropolitan-area-and-county/.

23. United States Census Bureau [Internet]. American Community Survey, 2009 - 2013 ACS 5-year data profiles; 2013 [cited 2020 May 19]. Available from: https://www.census.gov/acs/www/data/data-tablesand-tools/data-profiles.

24. Jones AF, Weinberg DH. The changing shape of the nation's income distribution; 2000. Current Population Reports P60-204. Washington (DC): US Department of Commerce, Economics and Statistics Administration, US Census Bureau.

25. Horowitz JM, Igielnik RK [Internet]. Trends in U.S. income and wealth inequality. Pew Research Center: Social \& Demographic Trends; 2020 [cited 2020 Sept 12]. Available from: https:// www.pewsocialtrends.org/2020/01/09/trends-inincome-and-wealth-inequality/.

26. NC Health Workforce [Internet]. North Carolina Health Professional Supply Data, North Carolina Health Professional Data System; 2019 [cited 2020 May 14]. Available from: https://nchealthworkforce. unc.edu/interactive/supply/.

27. UNC Charlotte [Internet]. Defining "urban," "rural," and "in-between" across the Carolinas UrbanRural Connections region. UNC Charlotte Urban Institute; 2020 [cited 2020 Sept 12]. Available from: https://ui.uncc.edu/pages/curc/definitions.

28. Buckman C, Liu IC, Cortright L, Tumin D, Syed S. The influence of local political trends on childhood vaccine completion in North Carolina. Soc Sci Med 2020;260:113187.

29. Campbell DJT, Ronksley PE, Manns BJ, for the Interdisciplinary Chronic Disease Collaboration, et al. The association of income with health behavior change and disease monitoring among patients with chronic disease. PLoS One 2014;9: e94007.

30. Centers for Disease Control and Prevention [Internet]. Cases in the U.S. CDC COVID Data Tracker; 2020 [cited 2020 May 16]. Available from: https://covid.cdc.gov/covid-data-tracker/?CDC_ AA_refVal=https $\% 3 \mathrm{~A} \% 2 \mathrm{~F} \% 2 \mathrm{Fwww} . c d c . g o v \%$ 2Fcoronavirus \%2F2019-ncov\%2Fcases-updates $\%$ 2Fcases-in-us.html\#cases_totalcases.

31. Dall T, West T, Iacobucci W. The complexities of physician supply and demand: projections from 2013 to 2025 . IHS Inc.; 2015. Final Report.

32. Streeter RA, Snyder JE, Kepley H, Stahl AL, Li T, Washko MM. The geographic alignment of primary care health professional shortage areas with markers for social determinants of health. PLoS One 2020;15:e0231443.

33. Playford D, May JA, Ngo H, Puddey IB. Decline in new medical graduates registered as general practitioners. Med J Aust 2020;212:421-2.

34. O'Connell PA, Wright SM. Declining interest in primary care careers. J Gen Intern Med 2003;18:230-1.

35. Rosser $W W$. The decline of family medicine as a career choice. C Can Med Assoc J 2002;166:1419.

36. Dalen JE, Ryan KJ, Alpert JS. Where have the generalists gone? They became specialists, then subspecialists. Am J Med 2017;130:766-8.

37. Georgetown University [Internet]. Rural and urban health. Health Policy Institute; 2003 [cited 2020 May 19]. Available from: https://hpi.georgetown. edu/rural/\#.

38. What is Medicaid's impact on access to care, health outcomes, and quality of care? Setting the record straight on the evidence [Internet]. Issue Brief. KFF; 2013 [cited 2020 July 18]. Available from: https://www.kff.org/report-section/what-is-medicaidsimpact-on-access-to-care-health-outcomes-andquality-of-care-setting-the-record-straight-on-theevidence-issue-brief/.

39. North Carolina and the ACA's Medicaid expansion [Internet]. healthinsurance.org; 2020 [cited 2020 July 18]. Available from: https://www.healthinsurance.org/ medicaid/north-carolina/.

40. Coplan B, Cawley J, Stoehr J. Physician assistants in primary care: trends and characteristics. Ann Fam Med 2013;11:75-9.

41. PAs in rural locations ready to meet primary care needs [Internet]. AAPA; 2018 [cited 2021 July 18]. Available from: https://www.aapa.org/news-central/ 2018/06/pas-rural-locations-ready-meet-primarycare-needs/. 
42. Jones CP. Toward the science and practice of antiracism: launching a national campaign against racism. Ethn Dis 2018;28:231-4.

43. Nau M. Economic elites and income inequality: economic elites, investments, and income inequality. Soc Forces 2013;92:437-61.

44. Baranoff $\mathrm{O}$ [Internet]. What's caused the rise in income inequality in the US? World Economic Forum; 2015 [cited 2020 May 19]. Available from: https://www.weforum.org/agenda/2015/05/whatscaused-the-rise-in-income-inequality-in-the-us.

45. Stone C, Trisi D, Sherman A, Beltrán J [Internet]. A guide to statistics on historical trends in income inequality. Center on Budget and Policy Priorities; 2014. Available from: https://www.cbpp.org/research/ poverty-and-inequality/a-guide-to-statistics-onhistorical-trends-in-income-inequality.

46. Galea S, Abdalla SM. COVID-19 pandemic, unemployment, and civil unrest: underlying deep racial and socioeconomic divides. JAMA 2020;324:227-8.

47. CDC [Internet]. Health equity considerations and racial and ethnic minority groups; 2020 [cited 2020 Sept 19]. Available from: https://www.cdc. gov/coronavirus/2019-ncov/community/healthequity/race-ethnicity.html.

48. Parker K, Horowitz JM, Brown A [Internet]. About half of lower-income Americans report household job or wage loss due to COVID-19. Pew Research Center; 2020 [cited 2020 May 19]. Available from: https://www.pewsocialtrends.org/2020/04/21/ about-half-of-lower-income-americans-reporthousehold-job-or-wage-loss-due-to-covid-19/.

49. Campbell KM, Infante Linares JL, Tumin D, Faison K, Heath MN. The role of North Carolina medical schools in producing primary care physicians for the state. J Prim Care Community Heal 2020;11:2150132720924263.

50. Kochhar R [Internet]. COVID-19 job losses hit Hispanic women, immigrants hardest. Pew Research Center Fact Tank; 2020 [cited 2020 Sept 12]. Available from: https://www.pewresearch. org/fact-tank/2020/06/09/hispanic-women-immigrantsyoung-adults-those-with-less-education-hit-hardestby-covid-19-job-losses/.

51. Fagan EB, Finnegan SC, Bazemore A, Gibbons C, Petterson S. Migration after family medicine residency: $56 \%$ of graduates practice within 100 miles of training. Am Fam Physician 2013;88:704. http:// www.aafp.org/afp/graham.One-Pagersareavailablefromthe GrahamCenterathttp://www.graham-center.org.http:// www.aafp.org/afp/2013/0601/od1.html.

52. Walker J, Quaile M, Tumin D. Rural employment of health care workers: a longitudinal cohort study. J Rural Health 2020;37:705-713. 